\title{
A AVALIAÇÃO DO ESTOQUE A PREÇO DE VENDA
}

\section{IVAN DE SÁ MOTTA}

0 autor apresenta método simples e esquemático para determinar o valor de custo do estoque avaliado a preço de venda.

O método de avaliação de estoque a preço de venda é mais comumente usado no comércio, embora haja indústrias que o adotem na avaliação de seu estoque de produtos acabados, devido a certas facilidades que oferece, do ponto de vista contábil. Para a emprêsa comercial, sobretudo a loja de varejo, a vantagem da adoção do método de avaliação a preço de venda está no fato de que as mercadorias vêm, normalmente, marcadas com êste valor.

Encontrar-se-á, no presente artigo, o tratamento numérico e contábil dêste método de avaliação. Apresentar-se-ão os resultados da aplicação do método sob uma forma tabelada, original e prática, que tem as vantagens de facilitar os cálculos e apresentar os resultados de maneira global. $\mathrm{Na}$ tabela aqui incluída, daremos não apenas os resultados finais, mas também os intermediários que levaram àqueles finais, a partir dos dados do problema que nela figuram.

Incluem-se, também, na parte final do trabalho, a título de ilustração, os lançamentos contábeis necessários ao uso do método. Sendo os valores de custo aquêles que devem, por lei, figurar nas demonstrações financeiras (balanço e conta

IVAN DE SÁ MOTTA - Professor-Adjunto da Escola de Administração de Emprêsas de São Paulo, Departamentos de Contabilidade e Finanças e de Administração da Produção. 
de lucros e perdas), fazemos a avaliação de estoque pelos valores de venda e, no encerramento do exercício, voltamos aos valores de custo que são, então, levados àquelas demonstrações.

\section{Simbolismo e Terminologia}

O tratamento numérico do problema pode ser simplificado pela introdução da terminologia e simbolismo abaixo apresentados, pois êstes permitem grande economia de palavras na ilustração dos conceitos e das operações aritméticas feitas. com base nesses conceitos.

I estoque inicial ao valor de custo

A compras ao valor de custo

F estoque final ao valor de custo

$T$ custo do produto vendido

$\Delta$ I margem do estoque inicial

$\Delta$ A margem da compra

$\Delta \mathrm{F}$ margem do estoque final

$\Delta T$ margem do custo do produto vendido

I' estoque inicial ao valor de venda

A' compras ao valor de venda

$F^{\prime}$ estoque final ao valor de venda

T' Vendas

Convém esclarecer que o conceito de margem pode ter umduplo significado : margem-acima e margem-abaixo. Êstes dois neologismos que aqui introduzimos traduzem as expressões inglêsas "mark-up" e "mark-down". Margem-acima éa quantia que, adicionada ao valor do custo dá o valor de venda. Margem-abaixo corresponde a uma eventual remarcação do preço de venda.

Suponhamos que o custo de uma mercadoria seja de 120 cruzeiros e que o seu preço de venda tenha sido fixado em 220 cruzeiros. A margem-acima seria, então, de 100 cruzeiros. Se, por uma razão qualquer, a mercadoria fôsse vendida ao preço de 200 cruzeiros, a margem-abaixo seria de 
20 cruzeiros e a margem total de 80 cruzeiros. A margem total é, pois, a soma algébrica das margens-acima (com sinal positivo) e das margens-abaixo (com sinal negativo) : $100-20=80$. No exemplo adiante descrito, consideramos sòmente a margem de 80 cruzeiros, que é a resultante da soma algébrica da margem-acima de 100 cruzeiros e da margem-abaixo de 20 cruzeiros.

Fórmulas Básicas

Com base na terminologia acima adotada, podemos escrever:

$$
\begin{aligned}
& \mathrm{I}+\Delta \mathrm{I}=\mathrm{I}^{\prime} \\
& \mathrm{A}+\Delta \mathrm{A}=\mathrm{A}^{\prime} \\
& \mathrm{F}+\Delta \mathrm{F}=\mathrm{F}^{\prime} \\
& \mathrm{T}+\Delta \mathrm{T}=\mathrm{T}^{\prime}
\end{aligned}
$$

O princípio de conservação monetária, aplicado aos valores de custo e aos valores de venda, leva às equações básicas seguintes :

$$
\begin{aligned}
& I+A=F+T \\
& I^{\prime}+A^{\prime}=F^{\prime}+T^{\prime}
\end{aligned}
$$

Conseqüentemente, temos também para as margens :

$$
\Delta \mathrm{I}+\Delta \mathrm{A}=\Delta \mathrm{F}+\Delta \mathrm{T}
$$

Ciclo de Avaliação do Estoque a Preço de Venda

A maneira pela qual se poderá aplicar as fórmulas acima descritas, na prática, será demonstrada por um exemplo simplificado.

1. Avaliação do Estoque Inicial a Preço de Venda I' - Suponhamos que, no início do período contábil em questão, exista um estoque ao valor de custo de 50 mil cruzeiros $(=I)$, ao qual se acrescenta uma margem de $60 \%$, ou seja, 30 mil cruzeiros $(=\Delta \mathrm{I})$. $\mathrm{O}$ valor dêste estoque ao preço de venda é, pois, de $80 \mathrm{mil}$ cruzeiros (= I').

2. Margem das Compras $\Delta A$ - Suponhamos ainda que, durante o período contábil em questão, tenham sido feitas compras no valor de 100 mil cruzeiros $(=\mathbf{A})$. Para cobrir as despesas de operação e obter o lucro necessário à justa remuneração do capital investido na emprêsa, estimou-se a 
necessidade de se trabalhar, durante o período, com a margem de $70 \%$, superior, portanto, à margem do estoque inicial. Esta margem de $70 \%$ corresponde ao valor monetário de $70 \times 100$ mil cruzeiros $=70$ mil cruzeiros $(=\Delta A)$.

100

3. Avaliação das Compras a Preço de Venda $A^{\prime}-\mathrm{O}$ valor, a preço de venda, das compras feitas durante o período contábil é, portanto de $100+70=170 \mathrm{mil}$ cruzeiros $\left(=\mathrm{A}^{\prime}\right)$.

4. Margem Sôbre o Valor de Venda Para o Estoque Inicial Este valor, que vem do exemplo acima, é de $30=0,375$ ou $37,5 \%\left(=\frac{\Delta \mathrm{I}}{\mathrm{I}^{\prime}}\right)$

80

5. Margem Sôbre o Valor de Venda Para as Compras - Este valor, também obtido do exemplo dado, é de $70=0,411$ ou $41,1 \%\left(=\frac{\Delta A}{A^{\prime}}\right)$

6. Margem Sôbre o Valor de Venda Para o Estoque Final do Periodo e as Vendas Durante o Periodo - Este valor é calculado como sendo a média ponderada das margens percentuais sôbre o valor de venda para o estoque inicial e as compras do período. Portanto: $\frac{30+70}{30+170}=\frac{100}{250}=0.4$ ou $40 \%\left(\frac{\Delta \mathrm{I}+\Delta \mathrm{A}}{\mathrm{I}^{\prime}+\mathrm{A}^{\prime}}\right)$.

7. Vendas Durante o Periodo $T^{\prime}$ - Suponhamos que, durante o período em questão, as vendas tenham sido de $200 \mathrm{mil}$ cruzeiros $\left(=\mathrm{T}^{\prime}\right)$.

8. Margem das Vendas Durante o Periodo $T$ - A margem percentual de $40 \%$ sôbre o valor de venda, ou de $66^{2} / 3 \%$

(1) Poderíamos ter utilizado o coeficiente $\frac{I+A}{I^{\prime}+A^{\prime}}$ em vez do coeficiente $\frac{\Delta \mathrm{I}+\Delta \mathrm{A}}{\mathrm{I}^{\prime}+\mathrm{A}^{\prime}}$ com o qual trabalhamos.

Acreditamos que os cálculos ficariam mais simples, mas não a apresentação global e a compreensão do método. 
sôbre o valor de custo, dá o valor monetário de 80 mil cruzeiros para a margem das vendas $(=\Delta \mathrm{T})$.

9. Custo de Estoque Vendido $T$ - Este custo será de $200-80=120$ mil cruzeiros $\left(T^{\prime}-\Delta T=T\right)$.

10. Estoque Final a Preço de Venda $F^{\prime}$ - Por diferença, podemos calcular êste valor : $80+170-200=50 \mathrm{mil} \mathrm{cru-}$ zeiros $\left(=\mathrm{I}^{\prime}+\mathrm{A}^{\prime}-\mathrm{T}^{\prime}=\mathrm{F}^{\prime}\right)$.

11. Margem Sôbre o Valor de Venda Para o Estoque Final - Também por diferença, podemos calcular esta margem, que é de $30+70-80=20$ mil cruzeiros $(=\Delta \mathrm{I}+\Delta \mathrm{A}-\Delta \mathrm{T}=\Delta \mathrm{F})$.

12. Estoque Final ao Valor de Custo $F$ - Conhecendo o valor do estoque final a preço de venda e a margem do estoque final, podemos determinar o valor do estoque final a preço de custo, que é de $50-20=30 \mathrm{mil}$ cruzeiros $\left(=F^{\prime}-\Delta F=F\right)$. Este valor pode ser também obtido somando o estoque inicial às compras e deduzindo o custo do estoque vendido, isto é, $50+100-120=30$ mil cruzeiros $(\mathrm{I}+\mathrm{A}-\mathrm{T}=\mathrm{F})$. Evidentemente, os dois valores têm que ser iguais. Quando ocorrem pequenas diferenças, estas são devidas às aproximações feitas nos cálculos.

QUADro I: AVALIAÇÃo do ESTOQUE A PREÇO dE VENDA

\begin{tabular}{|c|c|c|c|c|c|c|c|c|c|}
\hline \multicolumn{2}{|c|}{ ESTOQUE INHCIAL } & \multicolumn{2}{|c|}{ COMPRAS } & \multicolumn{2}{|c|}{$\begin{array}{l}\text { ESTOQUE INICIAL E } \\
\text { COMPRAS (SOMA OU } \\
\text { MEDIA PONDERADA }\end{array}$} & \multicolumn{2}{|c|}{ ESTOQUE FINAL } & \multicolumn{2}{|l|}{ VEND } \\
\hline simBolo & VALOR & simBolo & VALOR & sÍmBOLO & VALOR & SIMBOLO & VALOR & SIMBOLO & VALOR \\
\hline I & so. & A & 100 & $1+A$ & 150 & $\mathbf{F}$ & 30 & $\mathbf{T}$ & 120 \\
\hline$\Delta \mathrm{I} /$ & 0,6 & $\Delta \mathbf{A} / \mathbf{A}$ & 0,7 & $\frac{\Delta I+\Delta A}{I+A}$ & $0,662 / 3$ & $\Delta \boldsymbol{F} / \mathbf{F}$ & $0,662 / 3$ & $\Delta T / T$ & $0,66 \quad 2 / 3$ \\
\hline$\Delta \mathbf{I}$ & 30 & $\Delta A$ & 70 & $\Delta I+\Delta A$ & 100 & $\Delta F$ & 20 & $\Delta T$ & 80 \\
\hline$\Delta \mathrm{I}^{*}$ & 0,375 & $\Delta \mathbf{A} / \mathbf{A}^{\prime}$ & 0,411 & $\frac{\Delta^{\prime}+\Delta A}{l^{\prime}+A^{\prime}}$ & 0,4 & $\Delta \boldsymbol{F} / \mathbf{F}^{\prime}$ & 0,4 & $\Delta \mathrm{T} / \mathrm{T}$ & 0,4 \\
\hline $\mathbf{r}$ & 80 & $\mathbf{A}^{*}$ & 170 & $V^{\prime}+A^{\prime}$ & 250 & $\mathbf{F}^{\prime}$ & 50 & $T^{\prime}$ & 200 \\
\hline
\end{tabular}

NOTAS: para definiģäo dos simbelos, vide lexto.

Os dodos numóricos referem.se ao exemplo do texto.

Para que se possa acompanhar o ciclo da avaliação desde os elementos de custo até os valores de venda, apresentamos, no quadro 1 , em forma tabelada, um resumo dos passos que se devem seguir ao adotar o método proposto. 
R.A.E.

\section{Lançamentos Contábeis no Diário}

Utilizando os valores do exemplo dado, faremos os lançamentos contábeis exigidos pela aplicação do método.

$O$ estoque final do período anterior é o estoque inicial do período em questão e está lançado a preço de custo $(=50)$.

Faz-se o lançamento a preço de venda :

(1) Estoque

Margem do estoque inicial

Durante o período, foram feitas compras no valor de $100 \mathrm{mil}$ cruzeiros às quais se adicionou uma margem de 70 mil cruzeiros.

O lançamento pelo valor de custo será, então :

(2) Compras

Contas a pagar

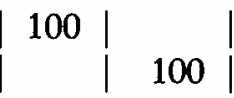

ao passo que o lançamento pelo valor de venda será :

Estoque a preço de venda

(3) Compras

Margem da compra

170

As vendas para o período foram de $200 \mathrm{mil}$ cruzeiros.

Contas a receber

(4)

Vendas

As vendas de 200 , com a margem de 80 , fazem o custo do estoque vendido durante o periodo igual a $120 \mathrm{mil}$ cruzeiros.

Custo do estoque vendido

(5) Margem do estoque vendido

Estoque a preço de venda

120

80

200

Utilizando-se o sistema de inventário perpétuo, sujeito a verificação pelo levantamento físico, determina-se o estoque final igual a 50, para o qual se calculou a margem de 20 .

Estoque ao valor de custo

(6) Margem do estoque final

Estoque a preço de venda

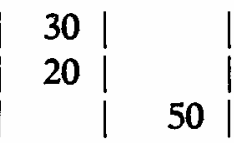




\section{Lançamentos Contábeis no Razão}

Os lançamentos do razão, feitos a partir dos lançamentos do diário, apresentam-se da seguinte forma :

Estoque a Preço de

Estoque

\begin{tabular}{ll|ll}
\hline Bal & 50 & 50 & $(1)$ \\
$(6)$ & 30 & 30 & \\
\hline & 80 & 80 \\
\hline 30 &
\end{tabular}

Margem

\begin{tabular}{cc|cc}
\hline (5) & 80 & 30 & $(1)$ \\
(6) & 20 & 70 & $(3)$ \\
\hline & 100 & 100 & \\
\hline
\end{tabular}

Contas a Pagar

$\overline{100 \quad(2)}$

Contas a Receber

(4) 200
Venda

(1) $80 \quad 200 \quad(5)$

(3) 170

50

$250 \quad 250$

Compras

(2) $100 \quad 1100 \quad(3)$

Vendas

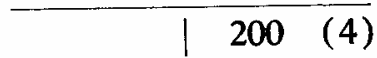

Custo do Estoque Vendido

(5) 120

Conclusões

Pretendemos, neste trabalho, oferecer uma solução de fácil aplicação prática ao problema da avaliação de estoque a preço de venda.

Acreditamos que o método aqui sugerido não só possa ser útil para a emprêsa comercial, mas também para a industrial, na avaliação de seu estoque de produtos acabados. 